\title{
A Monocentric, Retrospective Analysis of 61 Patients with Generalized Granuloma Annulare
}

\author{
Thierry M. Nordmann Joo-Ri Kim Reinhard Dummer Florian Anzengruber \\ Department of Dermatology, University Hospital Zurich, Zurich, Switzerland; Faculty of Medicine, University of \\ Zurich, Zurich, Switzerland
}

\section{Keywords}

Generalized granuloma annulare - Disseminated granuloma annulare · Granuloma annulare · Granulomatous skin disease

\begin{abstract}
Background: Granuloma annulare is a chronic noninfectious granulomatous skin condition with variable clinical presentations. Generalized granuloma annulare, defined as widespread disease with $>10$ skin lesions, accounts for $15 \%$ of all cases. Numerous associated diseases have been controversially discussed, most importantly diabetes mellitus, dyslipidemia, thyroid disease, malignancy and systemic infections. Objectives: The objective of our study is to describe disease characteristics, treatment outcome and associated diseases in patients treated at the Department of Dermatology of the University Hospital Zurich during the last 20 years. Methods: The hospital database was searched for patients with generalized granuloma annulare in the last 20 years (January 1, 1998, to December 31, 2017). Overall, 61 patients, 14 males and 47 females, were included in our study. The mean age was 58 years at first consultation. The diagnosis was verified clinically and histologically. Results: Generalized granuloma annulare occurred at a mean age of 55 years, more common-
\end{abstract}

ly in females. Pruritus was absent in $51 \%$ of all patients. Metabolic diseases including diabetes mellitus, hypercholesterinemia and hypertriglyceridemia were present in 10.5, 8.2 and $4.9 \%$, respectively. Thyroid disease was present in $9.8 \%$ and malignant disease in $23 \%$, including colorectal cancer, lymphoproliferative disease, squamous cell carcinoma of the esophagus, basal cell carcinoma and gynecological malignancy. Therapy was initiated in 92\%, while second- and thirdline therapy was performed in 70 and $39 \%$, respectively. Benefit during therapy (e.g., full and partial remission) was achieved in $39.3 \%$ during first-line, in $39.4 \%$ during secondline and in $33.8 \%$ during third-line treatment. Topical corticosteroids were the most commonly prescribed treatment, mostly leading to stable disease (46.6\%). Combined full and partial remission occurred in a large proportion of patients receiving UVA1 (45\%), PUVA (63.6\%) and intralesional triamcinolone acetonide (100\%). Conclusions: Generalized granuloma annulare is a mostly asymptomatic and benign disease with a strong tendency for treatment resistance. We suggest to screen all patients for dyslipidemia, thyroid disease and malignant disease. While randomized trials are needed, we suggest topical corticosteroids as the first-line treatment, intralesional triamcinolone acetonide for persistent solitary lesions and, if further treatment is needed, UVA1 or PUVA.

(C) 2020 The Author(s)

Published by S. Karger AG, Basel

\begin{tabular}{ll}
\hline karger@karger.com & $\begin{array}{l}\text { (c) 2020 The Author(s) } \\
\text { Published by S. Karger AG, Basel Openger } \\
\text { www.karger.com/drm }\end{array}$ \\
Karger & $\begin{array}{l}\text { This is an Open Access article licensed under the Creative Commons } \\
\text { Attribution-NonCommercial-4.0 International License (CC BY-NC) } \\
\text { (http://www.karger.com/Services/OpenAccessLicense), applicable to } \\
\text { the online version of the article only. Usage and distribution for com- } \\
\text { mercial purposes requires written permission. }\end{array}$
\end{tabular}

Florian Anzengruber

Department of Dermatology

University Hospital Zurich

Gloriastrasse 31, CH-8091 Zurich (Switzerland)

florian.anzengruber@usz.ch 


\section{Introduction}

Granuloma annulare (GA) is a noninfectious, granulomatous skin condition with variable clinical presentation [1]. Localized GA (LGA) is the most common form, presenting as erythematous, nonscaling, annular plaque mostly on distal extremities. Generalized GA (GGA) is defined as widespread disease with $>10$ skin lesions and accounts for $15 \%$ of all cases, typically presenting with widespread annular and erythematous plaques on the trunk and, in smaller amounts, the extremities [2]. While LGA is usually self-limiting within 2 years, GGA and atypical GA disease may persist for several years with a tendency for treatment resistance [3]. In a retrospective analysis of patients suffering from GGA, 25\% had disease persistence after 5 years and $10 \%$ after 10 years [4]. Mixed lymphocytic and histiocytic infiltrations have led to the hypothesis of a delayed-type hypersensitivity reaction. Up until today, the etiology of GA remains unclear. Numerous diseases have been controversially discussed to be associated with GGA, most importantly diabetes mellitus, dyslipidemia, thyroid disease, malignancy and infections such as human immunodeficiency virus [2]. In addition, certain medications have been associated with the onset of GA [5-7]. Given the controversial and only limited scientific data derived from retrospective analysis, a consensus on diagnostic procedures upon diagnosis of LGA and GGA does not exist. Evidence-based therapy is scarce and relies on case reports, case series and retrospective studies $[3,8]$. When necessary, high-potency topical or intralesional corticosteroids are considered first-line therapeutic options [2]. Alternatives include topical calcineurin inhibitors, cryosurgery, laser and light therapy, amongst others [9-11]. No randomized controlled trials evaluating different therapeutic regimens exist. The objective of our study is to describe disease characteristics, treatment outcome and associated diseases in all patients treated for GGA at the Department of Dermatology of the University Hospital Zurich during the last 20 years.

\section{Methods}

For further details, see the online supplementary material (see www.karger.com/doi/10.1159/000507247) (Fig. 1).

\section{Results}

\section{Baseline Characteristics}

Of 61 patients, $77 \%(n=47)$ were female and $23 \%$ $(n=14)$ male. The mean age at time of first visit in our clinic was 58 years ( $58.57 \pm 14.62$ years). The most common skin types were 2 and $3.85 \%(n=52)$ of all patients were Caucasians (Table 1).

Table 1. Cohort baseline characteristics

\begin{tabular}{lc}
\hline Patients, $n$ & 61 \\
Male, $n(\%)$ & $14(23)$ \\
Female, $n(\%)$ & $47(77)$ \\
Mean age \pm SD (median, range), years & $58.57 \pm 14.62$ \\
$\quad$ (at first consultation) & $(60,20-83)$ \\
Skin type, $n$ & \\
1 & 1 \\
2 & 14 \\
3 & 12 \\
4 & 1 \\
No data & 33 \\
Ethnicity, $n$ & \\
Caucasian & 52 \\
Turkish & 1 \\
Slavic & 5 \\
Lebanese & 1 \\
No data & 2 \\
\hline
\end{tabular}

Fig. 1. Flowchart of the Methods: inclu-

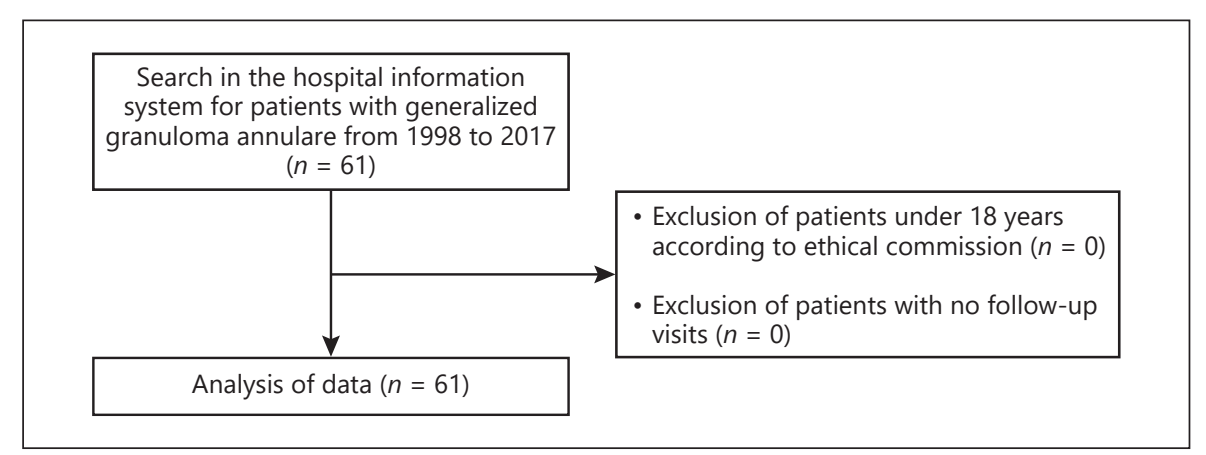
sion. 


\section{Disease Onset}

Reported disease onset occurred at a mean age of 55 years (55.64 \pm 15.97 years), with a diagnostic delay of $21.39 \pm 30.8$ months. The mean age at time of diagnosis was 58 years ( $58.12 \pm 14.65$ years). Pruritus was absent in $51 \%(n=31)$ of all patients, while mild to intermediate pruritus was present in $23 \%(n=14)$ and severe pruritus in $7 \%(n=4)$ of all patients. In $19 \%$ no data could be retrieved (Table 2).

\section{Treatment Outcome}

Therapy was initiated in the majority of patients $(n=56$, $92 \%)$. Second line-therapy was pursued in $70 \%(n=43)$ and third-line therapy in 39\% $(n=24)$. Of all patients receiving first-line therapy, full remission was achieved in $12.5 \%(n=7)$ and partial remission in $26.8 \%(n=15)$. Stable disease was seen in the majority of patients receiving first-line treatment $(42.9 \%, n=24)$ and only a minority had disease progression $(12.5 \%, n=7)$. Second-line treatment led to full remission in $11.6 \%(n=5)$ while $27.9 \%$ showed partial remission $(n=12)$. Stable disease was achieved in most patients under second-line treatment $(41.9 \%, n=18)$, and only a minority had disease progression $(12.5 \%, n=$ 12). In patients receiving third-line treatment, $20.8 \%(n=$ 5 ) achieved full remission, while only a minority had partial remission $(12.5 \%, n=3)$. Most patients had stable disease $(33.3 \%, n=8)$, and only 1 patient $(4.1 \%)$ progressed during third-line treatment (Fig. 2a).

Topical corticosteroids were the most commonly prescribed treatment modality, followed by UVA1, potassium iodatum, PUVA, UVB, intralesional triamcinolone acetonide and plaquenil. Topical steroids led to stable disease in most cases $(46.6 \%, n=27)$, and partial remission was achieved in 19\% $(n=11)$. While full remission oc- curred in only 6 patients (10.3\%), disease progression was observed in 5 patients receiving topical steroids (8.6\%). UVA1 led to full remission in 3 patients $(15.0 \%)$, and most patients achieved partial remission $(n=6,30 \%)$ or stable disease $(n=7,35 \%)$. Only 1 patient had disease progression upon UVA1 (5.0\%). Potassium iodatum treatment did not lead to full remission, while $25.0 \%$ showed partial remission $(n=3)$. Stable disease or disease progression occurred in 2 patients each $(16.7 \%)$ during potassium iodatum treatment. In patients receiving PUVA, 3 patients had full remission (27.3\%), while 4 patients showed partial remission (36.4\%) and 3 stable disease $(27.3 \%)$. Only 1 patient experienced disease progression $(9.1 \%)$ during PUVA treatment. No patient receiving UVB treatment achieved full remission, while $37.5 \%$ $(n=3)$ showed partial remission and $50 \%(n=4)$ stable disease. Only 1 patient had disease progression (12.5\%) after UVB treatment. In patients treated with intralesional triamcinolone acetonide, $60.0 \%(n=3)$ had full remission and $40.0 \%(n=2)$ partial remission, while no patients had disease progression. No patient taking Plaquenil experienced disease progression, while 1 patient achieved full remission $(20.0 \%), 2$ patients showed partial remission (40\%) and 1 patient showed stable disease (20\%) throughout treatment (Fig. 2b).

\section{Association to Other Diseases}

Among all patients, metabolic disease including diabetes mellitus, hypercholesterinemia and hypertriglyceridemia was present in $10.5 \%(n=6), 8.2 \%(n=5)$ and $4.9 \%$ $(n=3)$, respectively. Thyroid disease was present in $9.8 \%$ $(n=6)$. Infectious diseases were only present in a minority of patients. Malignant disease was present in 23\% ( $n=$ 14) of all patients (Table 3 ).
Table 2. Disease onset and symptoms

Analysis of 61 Patients with Generalized Granuloma Annulare

\begin{tabular}{lc} 
First onset & \\
Mean age \pm SD (median, range), years & $55.64 \pm 15.97(57,6-82)$ \\
No data, $n$ & 8 \\
Diagnosis & $21.39 \pm 30.8(11,0.75-160)$ \\
Mean duration \pm SD (median, range), months & 21 \\
$\quad$ No data, $n$ & $58.12 \pm 14.65(59,20-82)$ \\
Mean age \pm SD (median, range), years & 10 \\
$\quad$ No data, $n$ & \\
Pruritus, $n$ & 31 \\
None & 7 \\
Mild & 7 \\
Intermediate & 4 \\
Severe & 12 \\
No data & \\
\hline
\end{tabular}


Fig. 2. Treatment modalities and outcome.

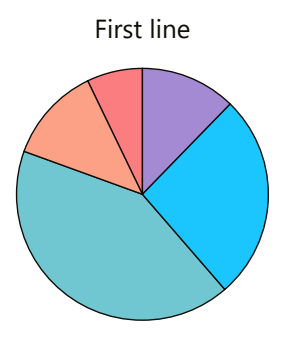

a

Total $=57$

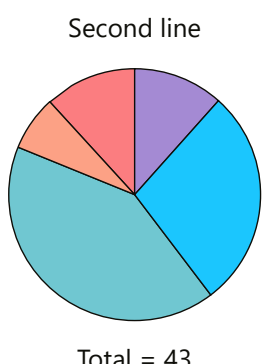

Total $=43$

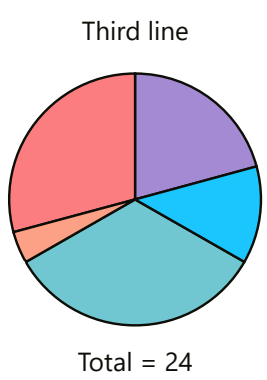

Treatment outcome

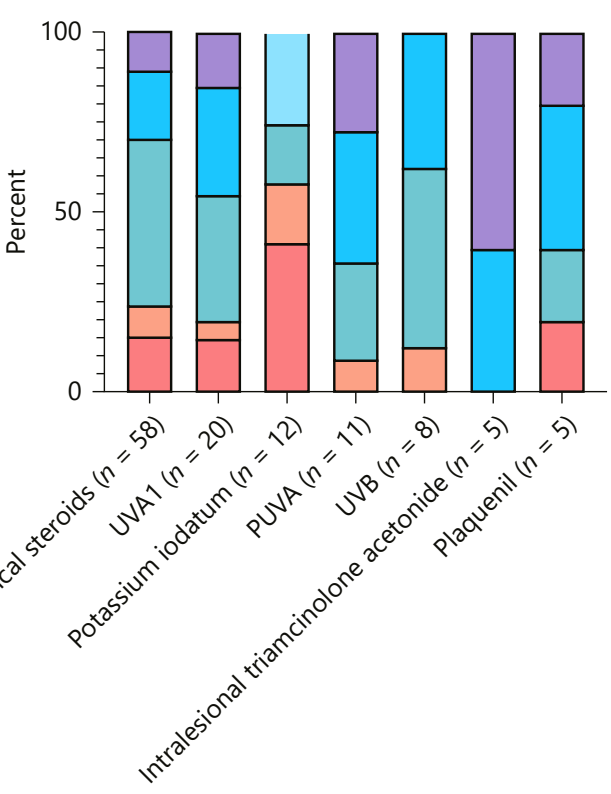

$\square$ Full remission $\square$ Partial remission $\square$ Stable disease $\square$ Disease progression $\square$ No data

\section{Discussion}

In this study, we analyzed the baseline characteristics, treatment modalities, treatment outcome and the presence of coexisting diseases in patients suffering from GGA treated at our dermatological department within the last 20 years.

In our cohort, GGA affected people in the second decade of life, with a female predominance. Female predominance has been described in GA and may relate to molecular events in germline maturation and repair [12]. Despite its relative distinct clinical presentation, diagnostic delay of 21 months occurred on average, which may be attributed to the limited cutaneous symptoms and hence limited patient distress. The vast majority of all patients, once diagnosed, received multiple lines of treatment. In line with the current literature, potent (e.g., mometasone furoate) to superpotent (e.g., clo- betasol propionate) topical corticosteroids were also the most commonly prescribed treatment modality in our cohort, followed by UVA1, potassium iodatum, PUVA, UVB, intralesional triamcinolone acetonide and Plaquenil [2]. Disappointingly, after 3 lines of treatment, full remission was achieved in only $27.9 \%(n=17)$ of all patients. This emphasizes both treatment resistance and lack of causal disease understanding. Of all therapeutic modalities applied, a beneficial effect (e.g., full and partial remission) occurred in a majority of patients receiving UVA1 $(45 \%, n=9 / 20)$, PUVA $(63.6 \%, n=7 / 11)$ and intralesional triamcinolone acetonide $(100 \%, n=5 / 5)$. Following the most common treatment modality (topical corticosteroids), only a minority of patients had disease progression $(8.6 \%, n=5 / 58)$, and most patients had stable disease throughout treatment $(46.6 \%, n=27 / 58)$, while full and partial remission occurred in only $29.3 \%$ $(n=17 / 58)$. 
Table 3. Coexisting diseases

\begin{tabular}{|c|c|}
\hline Hepatitis B/C, $n$ & 2 \\
\hline No & 59 \\
\hline No data & 0 \\
\hline Human immunodeficiency virus, $n$ & 1 \\
\hline No & 60 \\
\hline No data & 0 \\
\hline Borrelia, $n$ & 1 \\
\hline No & 58 \\
\hline No data & 2 \\
\hline Other infectious diseases, $n$ & 8 \\
\hline Tuberculosis & 2 \\
\hline Parasitic infection & 1 \\
\hline Cytomegalovirus infection & 1 \\
\hline Lues & 2 \\
\hline Molluscum contagiosum & 1 \\
\hline Urinary tract infection & 1 \\
\hline No & 53 \\
\hline No data & 0 \\
\hline Thyroid disease, $n$ & 6 \\
\hline Hypothyroidism & 4 \\
\hline Struma nodosum & 1 \\
\hline Thyroid dysfunction & 1 \\
\hline No & 55 \\
\hline No data & 0 \\
\hline \multicolumn{2}{|l|}{ Neoplasia, $n$} \\
\hline Basal cell carcinoma & 4 \\
\hline Colon carcinoma & 1 \\
\hline Rectum carcinoma & 1 \\
\hline Squamous cell carcinoma (esophagus) & 1 \\
\hline Mamma carcinoma & 2 \\
\hline Ovarian carcinoma & 1 \\
\hline Cervix carcinoma & 1 \\
\hline Acute myeloic leukemia & 1 \\
\hline Myeloproliferative neoplasia & 1 \\
\hline Chronic lymphatic leukemia & 1 \\
\hline Hodgkin lymphoma & 1 \\
\hline Lymphoma, not specified & 1 \\
\hline No & 47 \\
\hline No data & 1 \\
\hline Diabetes, $n$ & 6 \\
\hline No & 51 \\
\hline No data & 4 \\
\hline Hypercholesterolemia, $n$ & 5 \\
\hline No & 54 \\
\hline No data & 2 \\
\hline Hypertrigylceridemia, $n$ & 3 \\
\hline No & 56 \\
\hline No data & 2 \\
\hline
\end{tabular}

Numerous diseases have been associated with GGA, most importantly diabetes mellitus, dyslipidemia, thyroid disease, malignancy and infections. Despite initial reports on the association of diabetes mellitus and GA, contradictory results with both supporting and refuting data have been published [13-16]. In our cohort, diabetes mellitus was present in 6 of 57 patients (10.5\%). Given the reported diabetes mellitus prevalence of $7.4 \%( \pm 1.1 \%)$ in the Swiss population within the age group of 55-64 years, one may assume that the risk seems to be similar in patients suffering from GGA [17]. On the other hand, dyslipidemia is by now believed to be significantly increased in patients with GA, especially in the setting of GGA $[4,18]$. Similarly, several case reports and case-control studies have revealed a higher prevalence of autoimmune thyroid disease in patients suffering from LGA. In our cohort 9.8\% suffered from thyroid disease, $9.3 \%$ from hypercholesterolemia and $5.4 \%$ from hypertriglyceridemia. It remains unclear whether this represents an increased prevalence of thyroid disease or dyslipidemia, given the lack of control cases or data on the corresponding disease prevalence. Infectious diseases were present only in a minority of the patients, supporting the current hypothesis that infections may merely be an unspecific initiator [19]. Drug-induced GA has been reported, and involved medications include biologicals (tocilizumab, tumor necrosis factor inhibitors), pegylated interferon and amlodipine amongst others [5-7]. Despite the resolution of GA upon drug discontinuation, a proof of causal relationship does not exist. In our cohort, no drug-induced GA was suspected. Given the benign nature of GA, when a drug-induced etiology is suspected, discontinuation due to GA should be critically evaluated in the context of available and equal alternatives.

The occurrence of malignant disease at higher rates in patients suffering from GGA is controversially debated. Case reports have been published on the coexistence of malignancy in GGA patients [20-23]. In contrast, a recent case-control study did not identify an association of malignancy in patients suffering from GGA when compared to age-matched and sex-matched control patients [24]. In our cohort, malignant disease occurred in $23 \%(n=14)$ of all patients, including colorectal cancer, lymphoproliferative disease, squamous cell carcinoma of the esophagus, basal cell carcinoma and gynecologic malignancy.

A limitation of our study is the retrospective, monocentric design and the lack of a control cohort. The strength of our study is the big cohort size analyzed, considering the rareness of GGA. Our data contribute to the increasing effort in defining appropriate diagnostic procedures and treatment strategies in this benign, noninfectious granulomatous skin condition. Considering the current literature and our cohort data, we suggest to screen all patients for dyslipidemia and thyroid disease. Furthermore, given the uncertainty of coexistent malignant disease in generalized granuloma and the high rate in our cohort, screening (e.g., differential blood count, 
serum protein electrophoresis, chest X-ray, colonoscopy, cutaneous inspection and urological or gynecological examination) should be considered at a low threshold. Since cutaneous manifestations are usually asymptomatic, treatment resistant and carry the potential of spontaneous resolution, randomized trials are needed in order to define optimal treatment strategies. Careful consideration of potential treatment side effects should be emphasized. While no treatment may be necessary, we support the recommendation of topical corticosteroids as firstline treatment, given its limited side effect profile and stable disease control in nearly half the patients in our cohort. Single lesions may be additionally treated with intralesional triamcinolone acetonide, though this may not be relevant in the setting of widespread disease. If further treatment is needed, light therapy (UVA1 or PUVA) may represent a good alternative, yet only in patients not at increased risk for cutaneous carcinogenesis. Clearly, randomized, placebo-controlled trials are needed, in order to define a rational treatment algorithm. Further research is crucial in order to elucidate the pathophysiological changes underlying GA, which may eventually lead to causal treatment strategies.

\section{Key Message}

Treatment resistance is common in generalized granuloma annulare. Concurrent malignant disease should be ruled out.

\section{Statement of Ethics}

Ethic approval (BASEC No. ID 2018-00854) was obtained. All patients who were enrolled in this study signed a consent form.

\section{Disclosure Statement}

The authors have no conflicts of interest to declare.

\section{Funding Sources}

There was no funding for this study.

\section{Author Contributions}

All authors made substantial contributions to the conception of this paper. All authors have critically read this paper and have made their revisions, and they have now all approved this final version for submission.

\section{References}

1 Imadojemu S, Rosenbach M. Advances in Inflammatory Granulomatous Skin Diseases. Dermatol Clin. 2019 Jan;37(1):49-64.

2 Piette EW, Rosenbach M. Granuloma annulare: Pathogenesis, disease associations and triggers, and therapeutic options. J Am Acad Dermatol. 2016 Sep;75(3):467-79.

3 Wang J, Khachemoune A. Granuloma Annulare: A Focused Review of Therapeutic Options. Am J Clin Dermatol. 2018 Jun;19(3): 333-44.

4 Dabski K, Winkelmann RK. Generalized granuloma annulare: clinical and laboratory findings in 100 patients. J Am Acad Dermatol. 1989 Jan;20(1):39-47.

5 Lim AC, Hart K, Murrell D. A granuloma annulare-like eruption associated with the use of amlodipine. Australas J Dermatol. 2002 Feb; 43(1):24-7.

6 Voulgari PV, Markatseli TE, Exarchou SA, Zioga A, Drosos AA. Granuloma annulare induced by anti-tumour necrosis factor therapy. Ann Rheum Dis. 2008 Apr;67(4):567-70.

7 Pelechas E, Papoudou-Bai A, Voulgari PV, Drosos AA. Granuloma annulare development in a patient with rheumatoid arthritis treated with tocilizumab: case-based review. Rheumatol Int. 2019 Feb;39(2):353-7.

8 Keimig EL. Granuloma Annulare. Dermatol Clin. 2015 Jul;33(3):315-29.
9 Sparrow G, Abell E. Granuloma annulare and necrobiosis lipoidica treated by jet injector. $\mathrm{Br}$ J Dermatol. 1975 Jul;93(1):85-9.

10 Blume-Peytavi U, Zouboulis CC, Jacobi H, Scholz A, Bisson S, Orfanos CE. Successful outcome of cryosurgery in patients with granuloma annulare. Br J Dermatol. 1994 Apr;130(4): 494-7.

11 Verne SH, Kennedy J, Falto-Aizpurua LA, Griffith RD, Nouri K. Laser treatment of granuloma annulare: a review. Int J Dermatol. 2016 Apr;55(4):376-81.

12 Reisz C, Sandhu J. Granuloma annulare in women: evaluating the annular configuration in the context of germline repair. Women Health Open J. 2018;4(1):11-4.

13 Studer EM, Calza AM, Saurat JH. Precipitating factors and associated diseases in 84 patients with granuloma annulare: a retrospective study. Dermatology. 1996;193(4):364-8.

14 Spicuzza L, Salafia S, Capizzi A, Vitaliti G, Rotolo N, Leonardi S, et al. Granuloma annulare as first clinical manifestation of diabetes mellitus in children: a case report. Diabetes Res Clin Pract. 2012 Mar;95(3):e55-7.

15 Ran M, Wang Y. IMAGES IN CLINICAL MEDICINE. Generalized Granuloma Annulare Associated with Diabetes Mellitus. N Engl J Med. 2016 Sep;375(10):e21.

16 Alirezaei P, Farshchian M. Granuloma annulare: relationship to diabetes mellitus, thyroid disorders and tuberculin skin test. Clin Cosmet Investig Dermatol. 2017 Apr;10:141-5.
17 Bundesamt für Statistik. Personen mit Diabetes (je-d-14.03.03.02.02). Available from: http://www.bfs.admin.ch. 2018.

18 Wu W, Robinson-Bostom L, Kokkotou E, Jung HY, Kroumpouzos G. Dyslipidemia in granuloma annulare: a case-control study. Arch Dermatol. 2012 Oct; 148(10):1131-6.

19 Avitan-Hersh E, Sprecher H, Ramon M, Bergman R. Does infection play a role in the pathogenesis of granuloma annulare? J Am Acad Dermatol. 2013 Feb;68(2):342-3.

20 Vassileva S, Krasteva M, Marina S, Tsankov N. Widespread granuloma annulare and cervical adenocarcinoma. Int J Dermatol. 1992 Nov; 31(11):819.

21 Li A, Hogan DJ, Sanusi ID, Smoller BR. Granuloma annulare and malignant neoplasms. Am J Dermatopathol. 2003 Apr;25(2):113-6.

22 Shimizu S, Yasui C, Tsuchiya K. Atypical generalized granuloma annulare associated with two visceral cancers. J Am Acad Dermatol. 2006 May;54(5 Suppl):S236-8.

23 Mestre T, Rodrigues AM, Cardoso J. Disseminated granuloma annulare and hepatocellular carcinoma: association or coincidence? BMJ Case Rep. 2014 Oct;2014:pii: bcr2014205883.

24 Gabaldón VH, Haro-González-Vico V. Lack of an association between generalized granuloma annulare and malignancy: A case-control study. J Am Acad Dermatol. 2019 Jun;80(6): 1799-800. 